\title{
Transducer Pressure Probe Device
}

National Cancer Institute

\section{Source}

National Cancer Institute. Transducer Pressure Probe Device. NCI Thesaurus. Code C50299.

A probe device designed to convert a change in pressure into a varying electrical signal. 